\title{
Review
}

\section{Orphan G protein-coupled receptors (GPCRs): biological functions and potential drug targets}

\author{
Xiao-long TANG ${ }^{1}$, Ying WANG ${ }^{2}$, Da-li LI ${ }^{1}$, Jian $\mathrm{LUO}^{1, *}$, Ming-yao $\mathrm{LIU}^{1,2, *}$ \\ ${ }^{1}$ Shanghai Key Laboratory of Regulatory Biology, Institute of Biomedical Sciences and School of Life Sciences, East China Normal Uni- \\ versity, Shanghai 200241, China; ${ }^{2}$ Alkek Institute of Biosciences and Technology, Texas A\&M University Health Science Center, Hous- \\ ton, Texas 77030 , USA
}

The superfamily of G protein-coupled receptors (GPCRs) includes at least 800 seven-transmembrane receptors that participate in diverse physiological and pathological functions. GPCRs are the most successful targets of modern medicine, and approximately $36 \%$ of marketed pharmaceuticals target human GPCRs. However, the endogenous ligands of more than 140 GPCRs remain unidentified, leaving the natural functions of those GPCRs in doubt. These are the so-called orphan GPCRs, a great source of drug targets. This review focuses on the signaling transduction pathways of the Adhesion GPCR family, the LGR subfamily, and the PSGR subfamily, and their potential functions in immunology, development, and cancers. In this review, we present the current approaches and difficulties of orphan GPCR deorphanization and characterization.

Keywords: G protein-coupled receptors; orphan GPCR; deorphanization; Adhesion GPCR family; LGR subfamily; PSGR; Gpr48/Lgr4

Acta Pharmacologica Sinica (2012) 33: 363-371; doi: 10.1038/aps.2011.210; published online 27 Feb 2012

\section{Introduction}

GPCRs represent the largest superfamily and most diverse group of mammalian transmembrane proteins. The main characteristic feature of these proteins is that they share a common seven-transmembrane (7TM) configuration. GPCRs have attracted a great deal of interest owing to their numerous physiological and pathological roles in transducing extracellular signals into intracellular effector pathways through the activation of heterotrimeric $G$ protein by binding to a broad range of ligands, including proteins ${ }^{[1]}$, peptides ${ }^{[2]}$, organic compounds $^{[3,4]}$, and eicosanoids ${ }^{[5]}$. This makes GPCRs and their signal transduction pathways important specific targets for a variety of physiological functions and therapeutic approaches, ranging from the control of blood pressure, allergic response, kidney function, hormonal disorders, and neurological diseases to the progression of cancer ${ }^{[6]}$. Owing to the features of GPCR structure and function, approximately $36 \%$ of currently marketed drugs target human GPCRs ${ }^{[7]}$. GPCRs have huge potential in biomedical research and drug development.

Human GPCRs can be divided into five main families on the basis of phylogenetic criteria, Glutamate, Rhodopsin, Adhesion,

\footnotetext{
* To whom correspondence should be addressed.

E-mail jluo@bio.ecnu.edu.cn (Jian LUO); mliu@ibt.tamhsc.edu (Ming-yao LIU)

Received 2011-12-12 Accepted 2011-12-28
}

Frizzled/Taste2, and Secretin ${ }^{[8]}$. Among the five GPCRs families, Rhodopsin is the most studied. It comprises the largest group of GPCRs. Notably, in recent years, the leucine-rich repeatcontaining G-protein coupled receptor (LGR) subfamily, part of Rhodopsin, have displayed enormously important physiological functions in knockout mice studies especially LGR4 and LGR5. Olfactory receptors are also members of Rhodopsin family of GPCRs and are mainly expressed in sensory neurons of olfactory system. These form a multigene family. The PSGR subfamily belongs to the olfactory receptor group. The family has restricted expression in human prostate tissues and is upregulated in prostate cancer. The second largest GPCR family, with 33 members, is the Adhesion family. This family is very special because of its members' secondary structures, with distinctive long N-termini containing adhesion domains ${ }^{[8]}$. Limited studies have shown that Adhesion GPCRs are involved in the signaling of cell adhesion, motility, embryonic development, and the immune system. There are still GPCRs for which the natural ligands remain to be identified. These are called orphan GPCRs.

LGRs and PSGR belong to Rhodopsin subfamily and they represent as classical GPCRs in structure and signal transduction. On the other hand, Adhesion GPCRs are novel, and their structures and signal transduction are distinct to the classical GPCRs. In this review, we focused our discussion on LGR subfamily, PSGR subfamily, and Adhesion GPCRs family. We 
also discussed current screening systems for the deorphanization and characterization of the orphan GPCRs.

\section{Orphan GPCRs}

The first GPCR to be identified was rhodopsin in 1878. It was later proven that rhodopsin consists of the GPCR protein opsin and a reversibly covalently bound cofactor, retinal ${ }^{[9,10]}$. After completion of the human genome sequence in $2004^{[11,12]}$, the number of human GPCRs increased to about 800 based on the screening approaches, such as low-stringency hybridization $^{[13]}$, PCR-derived methods ${ }^{[14]}$, and bioinformatic analyses ${ }^{[15]}$. Besides the olfactory receptor family, more than 140 GPCRs have not yet been linked to endogenous ligands. These are the so-called orphan GPCRs (Figure 1) ${ }^{[16]}$.

\section{Biological functions of the LGR subfamily}

LGRs 4-8 are members of the rhodopsin GPCR family, which can be divided into two groups, LGRs 4, 5, and 6 and LGRs 7 and 8 in terms of their natural ligand. R-spondins have

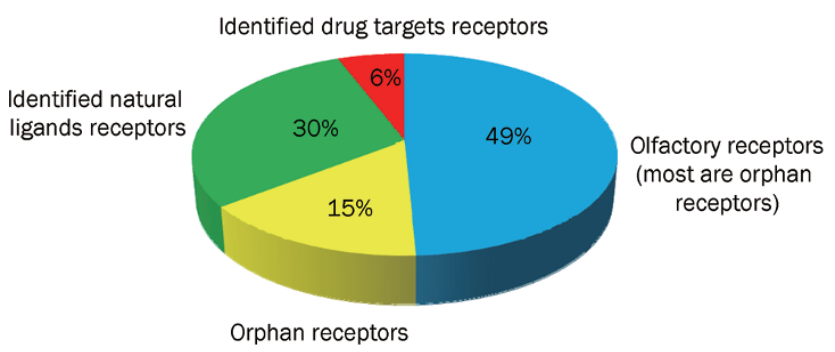

Figure 1. Percentage of the orphan GPCRs in GPCR superfamily. GPCRs constitute a large transmembrane family of more than 800 members. Among them, $6 \%$ are utilized as drug target in clinical applications, and $30 \%$ are natural ligand receptors. However, $49 \%$ are olfactory receptors (most of them are orphan GPCRs), and 15\% are orphan GPCRs. (Data were summarized from a review paper ${ }^{[122]}$ ) recently been identified as the ligands for LGRs 4, 5, and $6^{[17]}$. LGRs 7 and 8 are relaxin family peptide (RXFP) receptors ${ }^{[18]}$. According to sequence similarity, LGRs 4, 5, and 6 are closely related to each other, showing almost $50 \%$ identities. The three orphan receptors have a substantially large N-terminal extracellular domain (ECD) composed of 17 leucine rich repeats (LRR) (Figure 2) ${ }^{[19]}$. Lgr4, also known as Gpr48, has been reported to have many physiological functions by the generation of knockout mice. The loss of Lgr4 results in developmental defects in many areas, including intrauterine growth retardation associated with embryonic and perinatal lethality $^{[20]}$, abnormal renal development ${ }^{[21]}$, defective postnatal development of the male reproductive tract ${ }^{[22]}$, ocular anterior segment dysgenesis ${ }^{[23]}$, bone formation and remodeling dysfunction $^{[6]}$, impaired hair placode formation ${ }^{[24]}$, and defective development of the gall bladder and cystic ducts ${ }^{[25]}$. Lgr5 has been proven to be a marker of gastrointestinal tract and hair follicle stem cells ${ }^{[26,27]}$. Knockout of Lgr5 in mice leads to total neonatal lethality accompanied with ankyloglossia and gastrointestinal distension ${ }^{[28]}$. Lgr6 also has been shown to be a stem cell marker in hair follicles, and Lgr6-positive stem cells have been found to produce all cell lineages of the skin ${ }^{[2]}$. LGR4 and LGR5 are also highly expressed in several types of cancers. LGR5 is up-regulated in human colon and ovarian tumors and promotes cell proliferation and tumor formation in basal cell carcinoma ${ }^{[30,31]}$. Overexpression of LGR4 enhances cervical and colon cancer cell invasiveness and metastasis ${ }^{[32]}$. However, despite their critical function in development and cancer, LGR4 and LGR5 will still be considered orphan receptors until R-spondins reported to function as their natural ligands can be proven to regulate Wnt/ $\beta$-catenin signaling pathway. Some observations of Lgr4 and Lgr5 knockout mice have been strongly relevant to Wnt/ $\beta$-catenin signaling ${ }^{[33,34]}$. This suggests that LGR4 and LGR5 could be involved in the Wnt pathway. One author stated that
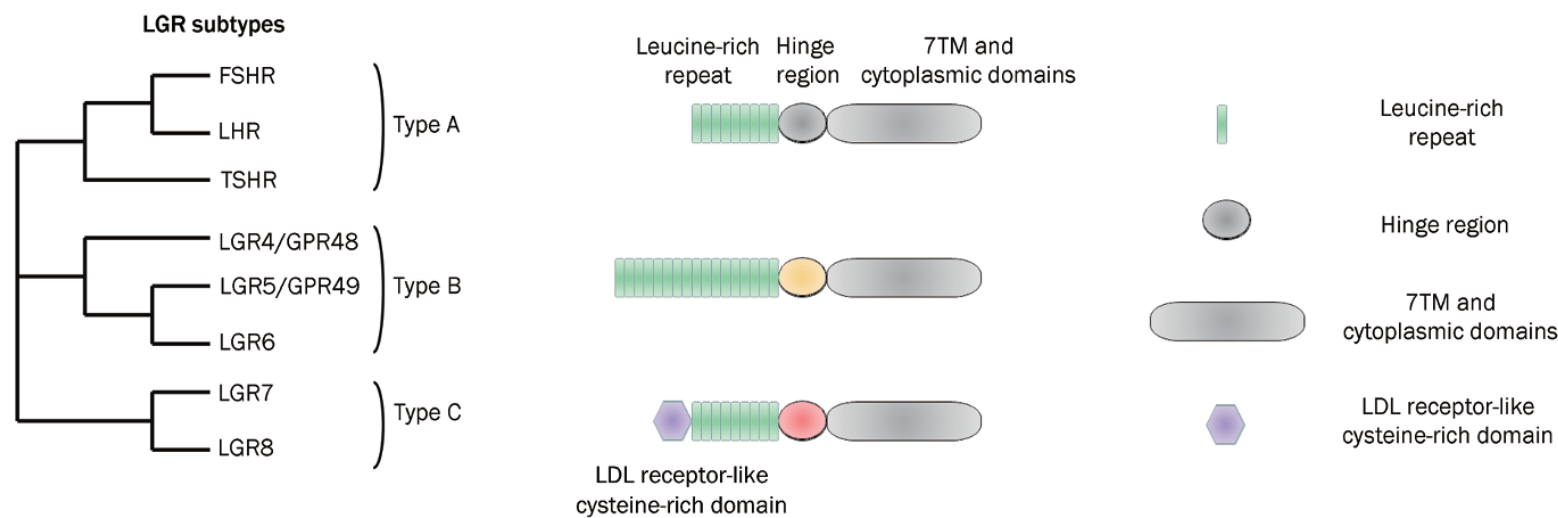

Figure 2. LGR subfamily GPCRs. The Type A LGRs includes the follicle-stimulating hormone receptor (FSHR), the luteinizing hormone receptor (LHR) and the thyroid-stimulating hormone receptor (TSHR). The Type B LGR comprises three members, Gpr48/LGR4, LGR5, and LGR6 which remain orphan GPCRs at the present time. By contrast, Type C LGRs have only two members, LGR7 and LGR8 which have been demonstrated to be the relaxin family receptors. Type A contains 9 LRRs in the ectodomain, whereas Type B contains 17 LRRs. By contrast, Type C has an N-terminal LDL receptor-like cysteine-rich domain not found in other LGRs. 7TM, seven-transmembrane; LDL, low-density lipoprotein; LRR, leucine-rich repeat; LGR, leucine-rich repeat-containing G-protein-coupled receptor; FSHR, follicle-stimulating hormone receptor; LHR, luteinizing hormone receptor; TSHR, thyroid-stimulating hormone receptor. 
R-spondins-Lgr4 induced the signal transduction pathway in a manner independent of $G$ proteins ${ }^{[17]}$. However, two independent groups have reported that Lgr4/Gpr48 is associated with the Gas-cAMP pathway by generating constitutively active forms of Lgr4/Gpr48 ${ }^{[23,35]}$. Therefore, the existence of endogenous ligands for the activation of classical G-protein coupled signaling pathways for Lgr4/Gpr48 is still a question. LGR7 and LGR8 share 54\% identity. Besides 10 LRRs motif, LGR7 and LGR8 also have an LDL class A (LDLa) motif in the N-terminal, which is an important domain for signal transduction (Figure 2). Traditionally, relaxin/LGR7 has been thought to be a hormone receptor for pregnancy and parturition $^{[18]}$. Recently, it has been reported that relaxin/LGR7 also has significant function in non-reproductive organs, such as the heart, and even plays a role in cancer growth and metastasis ${ }^{[36]}$. Insulin-like peptide 3 (INSL3), which is a ligand of LGR8, is highly expressed in the Leydig cells of the testis and knocking out Insl3 in mice generates a cryptorchid phenotype. However, reports have been conflicting with respect to LGR8 mutations related to human cryptorchidism ${ }^{[18]}$. The role of INSL3 in human adult male is still not clear.

\section{PSGRs subfamily in prostate cancer}

Mammalian olfactory receptors, which are the members of the Rhodopsin family of GPCRs and mainly expressed in sensory neurons of the olfactory epithelium in the nose, are used to sense the chemical environment ${ }^{[37]}$. Recently, some olfactory receptors have also been found in other organs. For example, MOR23 is expressed both in the olfactory epithelium and in sperm and functions as a chemosensing receptor during sperm-egg communication, thereby modulating fertilization in the reproductive system ${ }^{[38]}$. The new olfactory receptor family members PSGR1 and PSGR2 have been found to have restricted expression in human prostate tissues, as shown by Northern blot and real-time PCR analysis of over 20 different human tissue types ${ }^{[39-41]}$. PSGR subfamily expression increases significantly in the epithelial cells of prostate intraepithelial neoplasia (PIN) patients and in prostate cancer patients relative to non-cancerous controls and benign prostatic hyperplasia tissues, suggesting that the PSGR subfamily may play an important role in early prostate cancer development ${ }^{[42]}$. The PSGR subfamily has been proven to be strongly associated with the clinical parameters (clinical stages, Gleason scores, recurrence status, and metastasis) and its members could serve as biomarkers for prostate cancer ${ }^{[42,43]}$. PSGR subfamily transcripts even can be used as diagnostic markers in urine ${ }^{[44]}$. It has also been reported that PSGR expression detection together with the well-known prostate cancer marker prostatespecific antigen (PSA), prostate cancer gene 3 (PCA3), and a-methylacyl-CoA racemase (AMACR) can increases diagnostic specificity in the detection of prostate cancer ${ }^{[43-45]}$. Recently, Neuhaus EM et al reported that through intracellular $\mathrm{Ca}^{2+}$ flux using a bank of steroid hormones and through odorant-related compound screening, certain steroids and $\beta$-ionone have been proven to be active ligands for PSGR ${ }^{[46]}$. PSGR-induced $\mathrm{Ca}^{2+}$ signaling was found to require the involvement of endog- enous $\mathrm{Ca}^{2+}$-selective transient receptor potential vanilloid type 6 (TRPV6) channels ${ }^{[47]}$. Incubation of prostate cancer cells with $\beta$-ionone inhibits cell proliferation ${ }^{[46]}$. This suggests that PSGR signaling is also involved in prostate cancer cell progression.

\section{Adhesion GPCR family}

GPCRs in the Adhesion family have a relative long N-terminal domain, which contains many so-called adhesion domains (Figure 3). These adhesion domains only existed in some adhesion molecules, such as integrins, cadherins, and selectins; and the domains are thought to have adhesive properties. Another striking characteristic of all the Adhesion GPCRs is that there is a GPS (GPCR proteolytic site) domain linking the 7TM region to the extracellular domain, which acts as an autocatalytic site ${ }^{[48,49]}$. As a novel GPCRs family, most of the members are orphan and only a few of them have been identified as having natural ligands and functions.

\section{Adhesion GPCRs in immunology}

Immune response is coordinated by an assortment of membrane receptors, including TLRs, integrins, lectins, the Ig superfamily, selectins, and GPCRs, which are found on leukocytes $^{[10,50,51]}$. The first Adhesion GPCR to be discovered, epidermal growth factor-like module containing mucin-like receptor protein 1 (EMR1, F4/80 receptor), which is an epidermal growth factor (EGF)-seven transmembrane $(7 \mathrm{M})$ receptor, have a predominantly leukocyte-restricted expression pattern ${ }^{[52]}$. Though the expression of Emr1 is restricted, the function of this receptor remained unknown until the generation of Emr1 knock-out mice. The mouse model indicates that Emr1 is critical to the induction of $\mathrm{CD}^{+}$regulatory $\mathrm{T}$-cells in peripheral tolerance $^{[53]}$. Besides EMR1, the EGF-TM7 subfamily includes EMR2, EMR3, EMR4, and CD97, all of which belong to the Adhesion GPCR family. Unlike the highly specific expression of EMR1, the other EGF-TM7 receptors are expressed largely in myeloid cells (monocytes, macrophages, neutrophils, and dendritic cells) and in some lymphoid cells ( $\mathrm{T}$ and B cells) ${ }^{[54]}$. Chondroitin sulfate has recently been identified as the ligand for EMR2 and CD97, which mediate cell attachment ${ }^{[55]}$. CD97, the leukocyte activation antigen, also has been shown to bind to the complement regulatory protein DAF/CD55 (decay accelerating factor) and the longest splice variant of CD97 has the highest capacity to bind to CD55-expressing cells. Although CD97 and EMR2 differ by only 3 amino acids (in the EGF domain), the activity of EMR2 binding to CD55 is significantly weaker ${ }^{[56,57]}$. The precise function of the CD97-CD55 interaction is still not fully understood. Using knock-out mice and x-ray crystallography, Abbott RJ et al demonstrated that $\mathrm{T}$ cells and complement regulatory activities of CD55 occur on opposite faces of the molecule, suggesting that the CD97-CD55 complex might simultaneously regulate both the innate and adaptive immune responses ${ }^{[58,59]}$. EMR3 has been reported as a marker for mature granulocytes, and it can interact with the ligand that expresses at the surface of monocyte-derived macrophages and activated human neutrophils ${ }^{[60,61]}$. EMR4 has been reported to interact with a cell surface protein as a ligand 

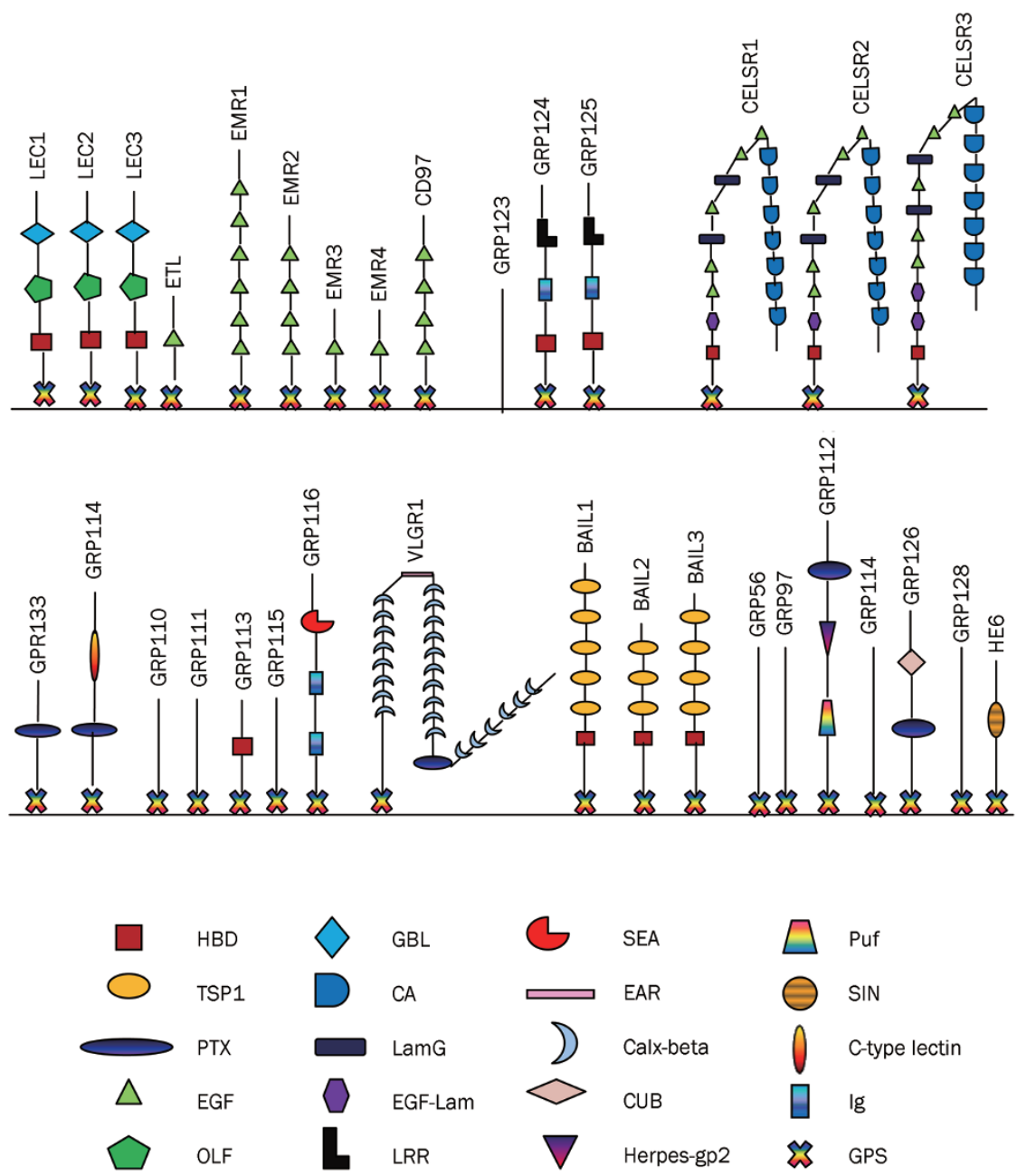

Figure 3. Schematic diagram of the extracellular $\mathrm{N}$-terminal domain within the Adhesion GPCRs. The extracellular $\mathrm{N}$-terminal domains of 33 Adhesion GPCRs was predicted by the RPS-BLAST against the conserved domain database (CCD). CA, cadherin domain; calx-beta, domain found in $\mathrm{Na}^{+}-\mathrm{Ca}^{2+}$ exchangers; CUB, resembles the structure of immunoglobins; EAR, epilepsy-associated repeat; EGF-Lam, laminin EGF-like domain; EGF, epidermal growth factor domain; HBD, hormone-binding domain; herpes-gp2, resembles the equine herpes virus glycoprotein gp2 structure; GBL, galactosebinding lectin domain; Ig, immunoglobulin domain; OLF, olfactomedin domain; LamG, laminin G domain; LRR, leucine-rich repeat domain; PTX, pentraxin domain; Puf, displays structural similarity to RNAbinding protein from the Puf family; SEA, domain found in sea-urchin sperm protein; SIN, resembles the primary structure of the SIN component of the histone deacetylase complex; TSP1, thrombospondin domain. C-type lectin, similar to the C-type lectin or carbohydrate-recognition domain; GPS, GPCR proteolytic site domain. on A20 B-lymphoma cells ${ }^{[62]}$.

\section{Adhesion GPCRs in development}

The most extensively studied Adhesion GPCRs in embryonic development are the so-called 7TM-cadherin subfamily (Celsr) Flamingo/Starry night). All the members of this subfamily posses extracellular domains containing nine atypical cadherin repeats which have linked the combination of EGF-like and laminin G-like domains ${ }^{[63]}$. The 7TM-cadherins are an evolutionarily conserved gene subfamily with homologues discovered from ascidians to mammals ${ }^{[63]}$. In mammals, the subfamily comprises 3 genes, Celsr 1, Celsr 2 , and Celsr3. There are 4 genes (fmila, fmilb, fmi2, and fmi3) in zebrafish and only one homologue, called flamingo and starry night, in Drosophila. Drosophila studies provide us with a distinct function view of Flamingo/Starry night as a core planar polarity protein ${ }^{[64]}$. Its functions include regulating dendrite extension from sensory neurons ${ }^{[65,66]}$, modulating target selection by photoreceptor axons $s^{[67]}$, accelerating axon advance from sensory and motor neurons ${ }^{[68]}$, and limiting ectopic neuromuscular junction formation and maintenance of motor axon terminals ${ }^{[69]}$. Gene knockout and knockdown of 7TM-cadherins has also confirmed this observation in vertebrates. 7TM-cadherins regulate morphogenetic movements, neural tube closure, orientation of sensory hair cells in inner ear, and hair follicle patterning ${ }^{[63,70-73]}$. Recently, Adhesion GPCRs Gpr124 and Gpr126, which are not 7TM-cadherins, have been shown to regulate the development of different tissues in mice. Gpr124 affects CNS-specific angiogenesis and Gpr126 affects Schwann cells to initiate myelination ${ }^{[74-77]}$. This suggests that more members of this family may be involved in development and that this may be due to the adhesive or other properties of $\mathrm{N}$-terminal domains.

\section{Adhesion GPCRs in cancers}

Because cell adhesion molecules have a vital role in cancer progression, it is reasonable to speculate that Adhesion GPCRs also play important functions in cancer progression and metastasis. Leukocyte Adhesion GPCR EMR2 has been proven to be overexpressed in human breast cancer and is associated with patient survival ${ }^{[78]}$. CD97 is involved in tumorenvironment interactions and mediates tumor invasion ${ }^{[79]}$. It has been reported that the 7TM-cadherin receptors may also be involved in human cancers, such as gastric cancer, lung cancer, and melanoma ${ }^{[80]}$. Interestingly, unlike other Adhesion GPCRs, GPR56 has been shown to suppress some cancer cell 
growth and metastasis through interacting with tissue transglutaminase (TG2) ${ }^{[81,82]}$.

\section{Signal transduction mediated by Adhesion GPCRs}

Most Adhesion GPCRs are orphan receptors, which is the main reason whether or not Adhesion GPCRs are involved in G protein signaling. In addition, the complicated structure of Adhesion GPCRs, comprising both largely ECD and 7TM domains, make it possible for Adhesion GPCRs to go through the signaling pathway in a G-protein-independent manner ${ }^{[83]}$. For example, Gpr124 regulates angiogenic sprouting into neural tissues through TGF-beta pathway in mouse ${ }^{[76]}$. BAI1 can function as an engulfment receptor in response to "eat me" signal phosphatidylserine, which leads to BAI1 directly bind and activate the ELMO/DOCK180/RAC module ${ }^{[84]}$. It has been reported that GPR124 and GPR125 can interact with several viral oncoproteins by its cytoplasmic PDZ domain. And the rat Ig-Hepta (GPR116) has been shown to form a homodimer that is linked by disulphide bonds. Moreover, this receptor undergoes two proteolytic cleavages, and cleaved product in the SEA domain might act as a ligand to bind to GPR116 $6^{[85-87]}$. Therefore, these 7TM receptors may mediate G-protein independent signaling pathway in cellular functions.

Though some Adhesion GPCRs go through G-proteinindependent pathways, others have been proven to go through the classic G-protein-dependent pathway. Lectomedin receptor-1 was co-purified with the $\mathrm{G}_{\mathrm{\alpha o}}{ }^{[88]}$. Also, GPR56 has been shown to form a complex with $\mathrm{G}_{\mathrm{q} / 11}$ and $\mathrm{G}_{12 / 13}$ in the neural progenitor cells ${ }^{[89,90]}$. Gpr126 modulates Schwann cells, initiating myelination by classic cAMP pathway ${ }^{[7]}$. Latrophilin, which is activated by the ligand LTX, can transduce the intercellular $\mathrm{Ca}^{2+}$ signal pathway. These observations indicate that this family can transmit signals through both classical G-protein-dependent and G-protein-independent mechanisms.

\section{Deorphanization strategy}

GPCRs are the most prominent family of pharmacological targets in biomedicine ${ }^{[91]}$. The deorphanization of orphan GPCRs is one of the most important missions in orphan GPCR research. Deorphanization is the process of identifying ligands that are highly selective for orphan GPCRs. In general, the standard assays are radio-ligand binding, calcium flux, GTPY binding, and modulation of cAMP levels ${ }^{[92-98]}$.

With the development of molecular technology, several lines of approaches have been used for deorphanization. The first, according to the sequence and function similarity, ligands of the identified receptors are used to examine GPCRs with identical sequences or domains. This sequence similarity strategy resulted in the identification of the ligands of Edg3 and Edg5, whose sequences are similar to that of the S1P receptors, with $>50 \%$ amino acid identity ${ }^{[99-101]}$. The function similarity strategy lead to the identification of the ligands of Lgr5 homologues, R-spondins, which stimulate the growth of intestinal stem cells ${ }^{[17]}$. However, this approach must be carefully evaluated because its predictions are not always accurate. For example, alkyl imidazole functions as dual histamine $\mathrm{H} 3 / \mathrm{H} 4$ receptor ligands, while histamine $\mathrm{H} 3 / \mathrm{H} 4$ receptors share very little sequence identity ${ }^{[102,103]}$. Although the EGF domain of CD97 and EMR2 share 97\% identity, only CD97 shows high affinity with CD55 but not with EMR2. The second strategy used to identify natural ligands works by determining the expression profile relationship between receptor and the putative ligand. This technique led to the identification of the receptors of RDC7 and RDC8 as adenosine $A_{1}$ and $A_{2 A}$ receptors, all of which are highly transcribed in the brain cortex, thyroid follicular cells, and testis ${ }^{[104,105]}$. The third technique is used to identify GPCRs that have specific expression profiles and distinct cytoplasm signal pathways. This method uses extracts of tissues that contain potential ligands to screen by the GPCRs mediated signaling assays. Some hormone proteins, such as nociptin, orexins, apelin, prolactin, and ghrelin, were successfully identified using this strategy ${ }^{[106-109]}$. The fourth strategy has been used successfully to deorphanize Adhesion GPCRs. It involves engineering recombinant soluble extracellular regions of Adhesion GPCRs with an Fc-fragment in N-terminal and biotinylation signal at the C-terminal. This acts as probe to screen the extracellular matrix components. This led to the identification of certain ligands for myeloid cell Adhesion $\mathrm{GPCR}^{[51,110]}$. In recent years, the so-called reverse pharmacology strategy has also been used to identify the ligands of orphan GPCRs ${ }^{[98]}$. This is carried out by expressing these orphan GPCRs in eukaryotic cells by DNA transfection and then coupling them to ligands to examine the binding affinity of the cells and ligands ${ }^{[111,112]}$. With this approach, many peptide hormones, including ghrelin, which stimulates hunger; kisspeptin and metastin, which are involved in puberty development and cancer metastasis; orexin and hypocretin, which mediate food intake and induce wakefulness and energy expenditure, have been discovered within the last decade ${ }^{[113]}$. However, the successful application of reverse pharmacology method depends on three major elements: sufficient orphan receptor expression, high-quality ligands and robust screening assays to detect receptor activation ${ }^{[114,115]}$. Fortunately, with development of membrane protein expression and purification techniques, neuropeptides and synthetic ligands have been applied to large-scale screening ${ }^{[16]}$. Of the three elements outlined above, choosing an appropriate detection assay is the most problematic.

The rate of GPCR deorphanization decreased drastically at the turn of the century, suggesting some gap the processes exit. Herein, we discuss several factors that may account for the problem. The greatest challenge in deorphanization of the receptors is the limited knowledge about them, especially with respect to their physiological functions and their roles as transmitters of signal pathways. Thus, experimental design is rendered difficult by the lack of signal transduction assays and positive controls ${ }^{[113]}$. Second, the majority of approaches to deorphanization rely on monitoring changes at the second messenger level, which is regulated by $\mathrm{G}$ proteins. However, GPCRs can transduce signal pathways diversely, sometimes even beyond $G$ proteins. In this case, identifying the relevant 
signaling pathway is key point to deorphanization. For example, some orphan GPCRs require accessory proteins for their activity. This working model has been shown in calcitonin GPCRs, which require RAMPs (receptor activity-modifying proteins) for their activation. To identify the ligand of this kind of GPCR, new screening assays for specific accessory proteins must be set $u^{[117,118]}$. Third, there is a possibility that some transmitters are only expressed at a particular time during the life span or at certain specific conditions ${ }^{[9]}$. Although it is risky and challenging, it is necessary to find more effective transmitters for deorphanization and put them to use. Lastly, some orphan GPCRs can form heterodimers with other GPCRs and function in a ligand-independent manner, and there is no outcome for the identification of the ligands of this kind of orphan GPCRs. For example, GABABR1 and GABABR2 form well-known heterodimer receptors and GABABR1 is involved in ligand-binding, whereas GABABR2 only acts as the signaling unit. GABABR2 is an orphan receptor in the heterodimer complex without any known ligand ${ }^{[119-121]}$.

\section{Perspectives in the research of orphan GPCRs}

In recent years, the numbers of new orphan GPCRs have increased and several members have been relatively well characterized. However, the progress of orphan GPCR function research has been hampered by the lack of identified ligands and by the unique structures of the GPCR themselves. Further investigation of their signaling pathways is valuable to understand the physiological and pathological roles of these new orphan GPCRs. The development of orphan GPCR knockout mice has also been shown to be a successful method for the characterization of their physiological and pathological functions. The knockout approach for orphan GPCRs are essential for our understanding of these receptor functions and their potential pathways. Functional and specific antibodies can serve probes not only for the ligands, but also for developing therapies for tumors and genetic disorders in which orphan GPCRs are involved. Although progress is very difficult, searching for the ligands of orphan GPCRs and identifying their physiological functions will continue. With recent discoveries of more and more orphan GPCR signaling pathways, understanding of their particular physiological functions and deorphanization for therapeutic purposes should accelerate in the coming years.

\section{Acknowledgements}

This work is partially supported by grants from National Basic Research Program of China (2012CB910400), National Natural Science Foundation of China (30800653, 30930055, and 81071437), the Science and Technology Commission of Shanghai Municipality (11DZ2260300), and by grants from NIH (5R01CA134731) and DOD (W81XWH-10-10147).

\section{References}

1 Parmentier M, Libert F, Maenhaut C, Lefort A, Gerard C, Perret J, et al. Molecular cloning of the thyrotropin receptor. Science 1989; 246: $1620-2$.
2 Masu Y, Nakayama K, Tamaki H, Harada Y, Kuno M, Nakanishi S. cDNA cloning of bovine substance-K receptor through oocyte expression system. Nature 1987; 329: 836-8.

3 Dixon RA, Kobilka BK, Strader DJ, Benovic JL, Dohlman HG, Frielle T, et al. Cloning of the gene and cDNA for mammalian beta-adrenergic receptor and homology with rhodopsin. Nature 1986; 321: 75-9.

4 Kobilka BK, MacGregor C, Daniel K, Kobilka TS, Caron MG, Lefkowitz RJ. Functional activity and regulation of human beta 2-adrenergic receptors expressed in Xenopus oocytes. J Biol Chem 1987; 262: 15796-802.

5 Felder CC, Briley EM, Axelrod J, Simpson JT, Mackie K, Devane WA. Anandamide, an endogenous cannabimimetic eicosanoid, binds to the cloned human cannabinoid receptor and stimulates receptormediated signal transduction. Proc Natl Acad Sci U S A 1993; 90: 7656-60.

6 Luo J, Zhou W, Zhou X, Li D, Weng J, Yi Z, et al. Regulation of bone formation and remodeling by G-protein-coupled receptor 48 . Development 2009; 136: 2747-56.

7 Rask-Andersen M, Almen MS, Schioth HB. Trends in the exploitation of novel drug targets. Nat Rev Drug Discov 2011; 10: 579-90.

8 Fredriksson R, Lagerstrom MC, Lundin LG, Schioth HB. The G-protein-coupled receptors in the human genome form five main families. Phylogenetic analysis, paralogon groups, and fingerprints. Mol Pharmacol 2003; 63: 1256-72.

9 Chung S, Funakoshi T, Civelli O. Orphan GPCR research. Br J Pharmacol 2008; 153: S339-46.

10 Oh DY, Kim K, Kwon HB, Seong JY. Cellular and molecular biology of orphan G protein-coupled receptors. Int Rev Cytol 2006; 252: 163-218.

11 Lander ES, Linton LM, Birren B, Nusbaum C, Zody MC, Baldwin J, et al. Initial sequencing and analysis of the human genome. Nature 2001; 409: 860-921.

12 Venter JC, Adams MD, Myers EW, Li PW, Mural RJ, Sutton GG, et al. The sequence of the human genome. Science 2001; 291: 1304-51.

13 Bunzow JR, Van Tol HH, Grandy DK, Albert P, Salon J, Christie M, et al. Cloning and expression of a rat $\mathrm{D}_{2}$ dopamine receptor cDNA. Nature 1988; 336: 783-7.

14 Libert F, Parmentier M, Lefort A, Dinsart C, Van Sande J, Maenhaut C, et al. Selective amplification and cloning of four new members of the G protein-coupled receptor family. Science 1989; 244: 569-72.

15 Vassilatis DK, Hohmann JG, Zeng H, Li F, Ranchalis JE, Mortrud MT, et al. The $G$ protein-coupled receptor repertoires of human and mouse. Proc Natl Acad Sci U S A 2003; 100: 4903-8.

16 Levoye A, Dam J, Ayoub MA, Guillaume JL, Jockers R. Do orphan G-protein-coupled receptors have ligand-independent functions? New insights from receptor heterodimers. EMBO Rep 2006; 7 : 1094-8.

17 Carmon KS, Gong X, Lin Q, Thomas A, Liu Q. R-spondins function as ligands of the orphan receptors LGR4 and LGR5 to regulate Wnt/ beta-catenin signaling. Proc Natl Acad Sci U S A 2011; 108: 114527.

18 Kong RC, Shilling PJ, Lobb DK, Gooley PR, Bathgate RA. Membrane receptors: structure and function of the relaxin family peptide receptors. Mol Cell Endocrinol 2010; 320: 1-15.

19 Hsu SY, Kudo M, Chen T, Nakabayashi K, Bhalla A, van der Spek PJ, et al. The three subfamilies of leucine-rich repeat-containing $G$ proteincoupled receptors (LGR): identification of LGR6 and LGR7 and the signaling mechanism for LGR7. Mol Endocrinol 2000; 14: 1257-71.

20 Mazerbourg S, Bouley DM, Sudo S, Klein CA, Zhang JV, Kawamura $\mathrm{K}$, et al. Leucine-rich repeat-containing, $\mathrm{G}$ protein-coupled receptor 4 null mice exhibit intrauterine growth retardation associated with 
embryonic and perinatal lethality. Mol Endocrinol 2004; 18: $2241-$ 54.

21 Kato S, Matsubara M, Matsuo T, Mohri Y, Kazama I, Hatano R, et al. Leucine-rich repeat-containing $\mathrm{G}$ protein-coupled receptor-4 (LGR4, Gpr48) is essential for renal development in mice. Nephron Exp Nephrol 2006; 104: e63-75.

22 Mendive F, Laurent P, Van Schoore G, Skarnes W, Pochet R, Vassart G. Defective postnatal development of the male reproductive tract in LGR4 knockout mice. Dev Biol 2006; 290: 421-34.

23 Weng J, Luo J, Cheng X, Jin C, Zhou X, Qu J, et al. Deletion of G protein-coupled receptor 48 leads to ocular anterior segment dysgenesis (ASD) through down-regulation of Pitx2. Proc Natl Acad Sci U S A 2008; 105: 6081-6.

24 Mohri Y, Kato S, Umezawa A, Okuyama R, Nishimori K. Impaired hair placode formation with reduced expression of hair follicle-related genes in mice lacking Lgr4. Dev Dyn 2008; 237: 2235-42.

25 Yamashita R, Takegawa Y, Sakumoto M, Nakahara M, Kawazu H, Hoshii T, et al. Defective development of the gall bladder and cystic duct in Lgr4-hypomorphic mice. Dev Dyn 2009; 238: 993-1000.

26 Barker N, van Es JH, Kuipers J, Kujala P, van den Born M, Cozijnsen $\mathrm{M}$, et al. Identification of stem cells in small intestine and colon by marker gene Lgr5. Nature 2007; 449: 1003-7.

27 Jaks V, Barker N, Kasper M, van Es JH, Snippert HJ, Clevers H, et al. Lgr5 marks cycling, yet long-lived, hair follicle stem cells. Nat Genet 2008; 40: 1291-9.

28 Morita H, Mazerbourg S, Bouley DM, Luo CW, Kawamura K, Kuwabara Y, et al. Neonatal lethality of LGR5 null mice is associated with ankyloglossia and gastrointestinal distension. Mol Cell Biol 2004; 24: 9736-43.

29 Snippert HJ, Haegebarth A, Kasper M, Jaks V, van Es JH, Barker N, et al. Lgr6 marks stem cells in the hair follicle that generate all cell lineages of the skin. Science 2010; 327: 1385-9.

30 McClanahan T, Koseoglu S, Smith K, Grein J, Gustafson E, Black S, et al. Identification of overexpression of orphan $\mathrm{G}$ protein-coupled receptor GPR49 in human colon and ovarian primary tumors. Cancer Biol Ther 2006; 5: 419-26.

31 Tanese K, Fukuma M, Yamada T, Mori T, Yoshikawa T, Watanabe W, et al. G-protein-coupled receptor GPR49 is up-regulated in basal cell carcinoma and promotes cell proliferation and tumor formation. Am J Pathol 2008; 173: 835-43.

32 Gao Y, Kitagawa K, Hiramatsu Y, Kikuchi H, Isobe T, Shimada M, et al. Up-regulation of GPR48 induced by down-regulation of p27Kip1 enhances carcinoma cell invasiveness and metastasis. Cancer Res 2006; 66: 11623-31.

33 Ootani A, Li X, Sangiorgi E, Ho QT, Ueno H, Toda S, et al. Sustained in vitro intestinal epithelial culture within a Wnt-dependent stem cell niche. Nat Med 2009; 15: 701-6.

34 Sato T, van Es JH, Snippert HJ, Stange DE, Vries RG, van den Born $\mathrm{M}$, et al. Paneth cells constitute the niche for Lgr5 stem cells in intestinal crypts. Nature 2011; 469: 415-8.

35 Gao Y, Kitagawa K, Shimada M, Uchida C, Hattori T, Oda T, et al Generation of a constitutively active mutant of human GPR48/LGR4, a G-protein-coupled receptor. Hokkaido Igaku Zasshi 2006; 81: 101-5, 7, 9.

36 Feng S, Agoulnik IU, Truong A, Li Z, Creighton CJ, Kaftanovskaya EM, et al. Suppression of relaxin receptor RXFP1 decreases prostate cancer growth and metastasis. Endocr Relat Cancer 2010; 17: 1021-33.

37 Spehr M, Munger SD. Olfactory receptors: G protein-coupled receptors and beyond. J Neurochem 2009; 109: 1570-83.

38 Fukuda N, Yomogida K, Okabe M, Touhara K. Functional charac- terization of a mouse testicular olfactory receptor and its role in chemosensing and in regulation of sperm motility. J Cell Sci 2004; 117: 5835-45.

39 Xu LL, Stackhouse BG, Florence K, Zhang W, Shanmugam N, Sesterhenn IA, et al. PSGR, a novel prostate-specific gene with homology to a $\mathrm{G}$ protein-coupled receptor, is overexpressed in prostate cancer. Cancer Res 2000; 60: 6568-72.

40 Weng J, Wang J, Hu X, Wang F, Ittmann M, Liu M. PSGR2, a novel G-protein coupled receptor, is overexpressed in human prostate cancer. Int J Cancer 2006; 118: 1471-80.

41 Xia C, Ma W, Wang F, Hua S, Liu M. Identification of a prostatespecific G-protein coupled receptor in prostate cancer. Oncogene 2001; 20: 5903-7.

42 Weng J, Wang J, Cai Y, Stafford LJ, Mitchell D, Ittmann M, et al. Increased expression of prostate-specific G-protein-coupled receptor in human prostate intraepithelial neoplasia and prostate cancers. Int J Cancer 2005; 113: 811-8.

43 Wang J, Weng J, Cai Y, Penland R, Liu M, Ittmann M. The prostatespecific G-protein coupled receptors PSGR and PSGR2 are prostate cancer biomarkers that are complementary to alpha-methylacyl-CoA racemase. Prostate 2006; 66: 847-57.

44 Rigau M, Morote J, Mir MC, Ballesteros C, Ortega I, Sanchez A, et al. PSGR and PCA3 as biomarkers for the detection of prostate cancer in urine. Prostate 2010; 70: 1760-7.

45 Rigau M, Ortega I, Mir MC, Ballesteros C, Garcia M, Llaurado M, et al. A three-gene panel on urine increases PSA specificity in the detection of prostate cancer. Prostate 2011; 71: 1736-45.

46 Neuhaus EM, Zhang W, Gelis L, Deng Y, Noldus J, Hatt H. Activation of an olfactory receptor inhibits proliferation of prostate cancer cells. J Biol Chem 2009; 284: 16218-25.

47 Spehr J, Gelis L, Osterloh M, Oberland S, Hatt H, Spehr M, et al. G protein-coupled receptor signaling via Src kinase induces endogenous human transient receptor potential vanilloid type 6 (TRPV6) channel activation. J Biol Chem 2011; 286: 13184-92.

48 Krasnoperov VG, Bittner MA, Beavis R, Kuang Y, Salnikow KV, Chepurny OG, et al. alpha-Latrotoxin stimulates exocytosis by the interaction with a neuronal G-protein-coupled receptor. Neuron 1997; 18: 925-37.

49 Baud V, Chissoe SL, Viegas-Pequignot E, Diriong S, N'Guyen VC, Roe BA, et al. EMR1, an unusual member in the family of hormone receptors with seven transmembrane segments. Genomics 1995; 26: 334-44.

50 Taylor PR, Martinez-Pomares L, Stacey M, Lin HH, Brown GD, Gordon S. Macrophage receptors and immune recognition. Annu Rev Immunol 2005; 23: 901-44.

51 Yona S, Lin HH, Stacey M. Immunity and adhesion-GPCRs. Adv Exp Med Biol 2010; 706: 121-7.

52 Austyn JM, Gordon S. F4/80, a monoclonal antibody directed specifically against the mouse macrophage. Eur J Immunol 1981; 11: 805-15.

53 Lin HH, Faunce DE, Stacey M, Terajewicz A, Nakamura T, ZhangHoover J, et al. The macrophage F4/80 receptor is required for the induction of antigen-specific efferent regulatory $T$ cells in peripheral tolerance. J Exp Med 2005; 201: 1615-25.

54 Kwakkenbos MJ, Pouwels W, Matmati M, Stacey M, Lin HH, Gordon $\mathrm{S}$, et al. Expression of the largest CD97 and EMR2 isoforms on leukocytes facilitates a specific interaction with chondroitin sulfate on B cells. J Leukoc Biol 2005; 77: 112-9.

55 Stacey M, Chang GW, Davies JQ, Kwakkenbos MJ, Sanderson RD, Hamann J, et al. The epidermal growth factor-like domains of the human EMR2 receptor mediate cell attachment through chondroitin 
sulfate glycosaminoglycans. Blood 2003; 102: 2916-24.

56 Hamann J, Vogel B, van Schijndel GM, van Lier RA. The seven-span transmembrane receptor CD97 has a cellular ligand (CD55, DAF). J Exp Med 1996; 184: 1185-9.

57 Hamann J, Stortelers C, Kiss-Toth E, Vogel B, Eichler W, van Lier RA. Characterization of the CD55 (DAF)-binding site on the seven-span transmembrane receptor CD97. Eur J Immunol 1998; 28: 1701-7.

58 Abbott RJ, Spendlove I, Roversi P, Fitzgibbon H, Knott V, Teriete P, et al. Structural and functional characterization of a novel $T$ cell receptor co-regulatory protein complex, CD97-CD55. J Biol Chem 2007; 282: 22023-32.

59 Capasso M, Durrant LG, Stacey M, Gordon S, Ramage J, Spendlove I. Costimulation via CD55 on human CD4+ T cells mediated by CD97. J Immunol 2006; 177: 1070-7.

60 Matmati M, Pouwels W, van Bruggen R, Jansen M, Hoek RM, Verhoeven AJ, et al. The human EGF-TM7 receptor EMR3 is a marker for mature granulocytes. J Leukoc Biol 2007; 81: 440-8.

61 Stacey M, Lin HH, Hilyard KL, Gordon S, McKnight AJ. Human epidermal growth factor (EGF) module-containing mucin-like hormone receptor 3 is a new member of the EGF-TM7 family that recognizes a ligand on human macrophages and activated neutrophils. J Biol Chem 2001; 276: 18863-70.

62 Stacey M, Chang GW, Sanos SL, Chittenden LR, Stubbs L, Gordon S, et al. EMR4, a novel epidermal growth factor (EGF)-TM7 molecule up-regulated in activated mouse macrophages, binds to a putative cellular ligand on B lymphoma cell line A20. J Biol Chem 2002; 277: 29283-93.

63 Formstone CJ. 7TM-Cadherins: developmental roles and future challenges. Adv Exp Med Biol 2010; 706: 14-36.

64 Lawrence PA, Casal J, Struhl G. Cell interactions and planar polarity in the abdominal epidermis of Drosophila. Development 2004; 131: 4651-64.

65 Grueber WB, Jan LY, Jan YN. Tiling of the Drosophila epidermis by multidendritic sensory neurons. Development 2002; 129: 2867-78.

66 Sweeney NT, Li W, Gao FB. Genetic manipulation of single neurons in vivo reveals specific roles of flamingo in neuronal morphogenesis. Dev Biol 2002; 247: 76-88.

67 Chen PL, Clandinin TR. The cadherin Flamingo mediates leveldependent interactions that guide photoreceptor target choice in Drosophila. Neuron 2008; 58: 26-33.

68 Steinel MC, Whitington PM. The atypical cadherin Flamingo is required for sensory axon advance beyond intermediate target cells. Dev Biol 2009; 327: 447-57.

69 Bao H, Berlanga ML, Xue M, Hapip SM, Daniels RW, Mendenhall JM, et al. The atypical cadherin flamingo regulates synaptogenesis and helps prevent axonal and synaptic degeneration in Drosophila. Mol Cell Neurosci 2007; 34: 662-78.

70 Curtin JA, Quint E, Tsipouri V, Arkell RM, Cattanach B, Copp AJ, et al. Mutation of Celsr1 disrupts planar polarity of inner ear hair cells and causes severe neural tube defects in the mouse. Curr Biol 2003; 13: 1129-33.

71 Carreira-Barbosa F, Kajita M, Morel V, Wada H, Okamoto H, Martinez Arias $\mathrm{A}$, et al. Flamingo regulates epiboly and convergence/extension movements through cell cohesive and signalling functions during zebrafish gastrulation. Development 2009; 136: 383-92.

72 Ciruna B, Jenny A, Lee D, Mlodzik M, Schier AF. Planar cell polarity signalling couples cell division and morphogenesis during neurulation. Nature 2006; 439: 220-4.

73 Ravni A, Qu Y, Goffinet AM, Tissir F. Planar cell polarity cadherin Celsr1 regulates skin hair patterning in the mouse. J Invest Dermatol 2009; 129: 2507-9.
74 Monk KR, Naylor SG, Glenn TD, Mercurio S, Perlin JR, Dominguez C, et al. A G protein-coupled receptor is essential for Schwann cells to initiate myelination. Science 2009; 325: 1402-5.

75 Kuhnert F, Mancuso MR, Shamloo A, Wang HT, Choksi V, Florek M, et al. Essential regulation of CNS angiogenesis by the orphan $\mathrm{G}$ proteincoupled receptor GPR124. Science 2010; 330: 985-9.

76 Anderson KD, Pan L, Yang XM, Hughes VC, Walls JR, Dominguez MG, et al. Angiogenic sprouting into neural tissue requires Gpr124, an orphan G protein-coupled receptor. Proc Natl Acad Sci U S A 2011; 108: 2807-12.

77 Monk KR, Oshima K, Jors S, Heller S, Talbot WS. Gpr126 is essential for peripheral nerve development and myelination in mammals. Development 2011; 138: 2673-80.

78 Davies JQ, Lin HH, Stacey M, Yona S, Chang GW, Gordon S, et al. Leukocyte adhesion-GPCR EMR2 is aberrantly expressed in human breast carcinomas and is associated with patient survival. Oncol Rep 2011; 25: 619-27.

79 Galle J, Sittig D, Hanisch I, Wobus M, Wandel E, Loeffler M, et al. Individual cell-based models of tumor-environment interactions: Multiple effects of CD97 on tumor invasion. Am J Pathol 2006; 169: 1802-11.

80 Katoh M. WNT/PCP signaling pathway and human cancer (review). Oncol Rep 2005; 14: 1583-8.

81 Xu L, Begum S, Hearn JD, Hynes RO. GPR56, an atypical G proteincoupled receptor, binds tissue transglutaminase, TG2, and inhibits melanoma tumor growth and metastasis. Proc Natl Acad Sci U S A 2006; 103: 9023-8.

82 Xu L, Begum S, Barry M, Crowley D, Yang L, Bronson RT, et al. GPR56 plays varying roles in endogenous cancer progression. Clin Exp Metastasis 2010; 27: 241-9.

83 Mizuno N, Itoh $\mathrm{H}$. Signal transduction mediated through adhesionGPCRs. Adv Exp Med Biol 2010; 706: 157-66.

84 Park D, Tosello-Trampont AC, Elliott MR, Lu M, Haney LB, Ma Z, et al. BAI1 is an engulfment receptor for apoptotic cells upstream of the ELMO/Dock180/Rac module. Nature 2007; 450: 430-4.

85 Abe J, Fukuzawa T, Hirose S. Cleavage of Ig-Hepta at a "SEA" module and at a conserved $\mathrm{G}$ protein-coupled receptor proteolytic site. J Biol Chem 2002; 277: 23391-8.

86 Abe J, Suzuki H, Notoya M, Yamamoto T, Hirose S. Ig-hepta, a novel member of the G protein-coupled hepta-helical receptor (GPCR) family that has immunoglobulin-like repeats in a long $\mathrm{N}$-terminal extracellular domain and defines a new subfamily of GPCRs. J Biol Chem 1999; 274: 19957-64.

87 Fukuzawa T, Hirose S. Multiple processing of Ig-Hepta/GPR116, a G protein-coupled receptor with immunoglobulin (Ig)-like repeats, and generation of EGF2-like fragment. J Biochem 2006; 140: 445-52.

88 Lelianova VG, Davletov BA, Sterling A, Rahman MA, Grishin EV, Totty $N F$, et al. Alpha-latrotoxin receptor, latrophilin, is a novel member of the secretin family of $\mathrm{G}$ protein-coupled receptors. J Biol Chem 1997; 272: 21504-8.

89 Little KD, Hemler ME, Stipp CS. Dynamic regulation of a GPCRtetraspanin-G protein complex on intact cells: central role of CD81 in facilitating GPR56-Galpha q/11 association. Mol Biol Cell 2004; 15: 2375-87.

90 Iguchi T, Sakata K, Yoshizaki K, Tago K, Mizuno N, Itoh H. Orphan $G$ protein-coupled receptor GPR56 regulates neural progenitor cell migration via a G alpha 12/13 and Rho pathway. J Biol Chem 2008; 283: 14469-78.

91 Lappano R, Maggiolini M. G protein-coupled receptors: novel targets for drug discovery in cancer. Nat Rev Drug Discov 2011; 10: 47-60.

92 Crouch MF, Osmond RI. New strategies in drug discovery for GPCRs: 
high throughput detection of cellular ERK phosphorylation. Comb Chem High Throughput Screen 2008; 11: 344-56.

93 Bikkavilli RK, Tsang SY, Tang WM, Sun JX, Ngai SM, Lee SS, et al. Identification and characterization of surrogate peptide ligand for orphan $\mathrm{G}$ protein-coupled receptor mas using phage-displayed peptide library. Biochem Pharmacol 2006; 71: 319-37.

94 Overton HA, Babbs AJ, Doel SM, Fyfe MC, Gardner LS, Griffin G, et al. Deorphanization of a $\mathrm{G}$ protein-coupled receptor for oleoylethanolamide and its use in the discovery of small-molecule hypophagic agents. Cell Metab 2006; 3: 167-75.

95 Pausch MH. G-protein-coupled receptors in Saccharomyces cerevisiae: high-throughput screening assays for drug discovery. Trends Biotechnol 1997; 15: 487-94.

96 Bates B, Zhang L, Nawoschik S, Kodangattil S, Tseng E, Kopsco D, et al. Characterization of Gpr101 expression and G-protein coupling selectivity. Brain Res 2006; 1087: 1-14.

97 Suga $\mathrm{H}$, Haga $\mathrm{T}$. Ligand screening system using fusion proteins of $\mathrm{G}$ protein-coupled receptors with $\mathrm{G}$ protein alpha subunits. Neurochem Int 2007; 51: 140-64.

98 Howard AD, McAllister G, Feighner SD, Liu Q, Nargund RP, Van der Ploeg LH, et al. Orphan G-protein-coupled receptors and natural ligand discovery. Trends Pharmacol Sci 2001; 22: 132-40.

99 Okamoto H, Takuwa N, Yatomi Y, Gonda K, Shigematsu H, Takuwa Y. EDG3 is a functional receptor specific for sphingosine 1-phosphate and sphingosylphosphorylcholine with signaling characteristics distinct from EDG1 and AGR16. Biochem Biophys Res Commun 1999; 260: 203-8.

100 An S, Zheng Y, Bleu T. Sphingosine 1-phosphate-induced cell proliferation, survival, and related signaling events mediated by $\mathrm{G}$ protein-coupled receptors Edg3 and Edg5. J Biol Chem 2000; 275: 288-96.

101 Pyne S, Pyne NJ. Sphingosine 1-phosphate signalling in mammalian cells. Biochem J 2000; 349: 385-402.

102 Lovenberg TW, Roland BL, Wilson SJ, Jiang X, Pyati J, Huvar A, et al. Cloning and functional expression of the human histamine $\mathrm{H} 3$ receptor. Mol Pharmacol 1999; 55: 1101-7.

103 Oda T, Morikawa N, Saito Y, Masuho Y, Matsumoto S. Molecular cloning and characterization of a novel type of histamine receptor preferentially expressed in leukocytes. J Biol Chem 2000; 275: 36781-6.

104 Maenhaut C, Van Sande J, Libert F, Abramowicz M, Parmentier M, Vanderhaegen JJ, et al. RDC8 codes for an adenosine A2 receptor with physiological constitutive activity. Biochem Biophys Res Commun 1990; 173: 1169-78.

105 Libert F, Schiffmann SN, Lefort A, Parmentier M, Gerard C, Dumont JE, et al. The orphan receptor CDNA RDC7 encodes an A1 adenosine receptor. EMBO J 1991; 10: 1677-82.

106 de Lecea L, Kilduff TS, Peyron C, Gao X, Foye PE, Danielson PE, et al. The hypocretins: hypothalamus-specific peptides with neuroexcitatory activity. Proc Natl Acad Sci U S A 1998; 95: 322-7.
107 Hinuma S, Habata Y, Fujii R, Kawamata Y, Hosoya M, Fukusumi S, et al. A prolactin-releasing peptide in the brain. Nature 1998; 393: 272-6.

108 Sakurai T, Amemiya A, Ishii M, Matsuzaki I, Chemelli RM, Tanaka H, et al. Orexins and orexin receptors: a family of hypothalamic neuropeptides and $G$ protein-coupled receptors that regulate feeding behavior. Cell 1998; 92: 573-85.

109 Tatemoto K, Hosoya M, Habata Y, Fujii R, Kakegawa T, Zou MX, et al. Isolation and characterization of a novel endogenous peptide ligand for the human APJ receptor. Biochem Biophys Res Commun 1998; 251: 471-6.

110 Lin HH, Chang GW, Huang YS, Hsiao CC, Stacey M, Gordon S. Multivalent protein probes for the identification and characterization of cognate cellular ligands for myeloid cell surface receptors. Methods Mol Biol 2009; 531: 89-101.

111 Libert F, Vassart G, Parmentier M. Current developments in G-protein-coupled receptors. Curr Opin Cell Biol 1991; 3: 218-23.

112 Mills A, Duggan MJ. Orphan seven transmembrane domain receptors: reversing pharmacology. Trends Biotechnol 1994; 12: 47-9.

113 Ozawa A, Lindberg I, Roth B, Kroeze WK. Deorphanization of novel peptides and their receptors. AAPS J 2010; 12: 378-84.

114 Marchese A, George SR, Kolakowski LF Jr, Lynch KR, O'Dowd BF. Novel GPCRs and their endogenous ligands: expanding the boundaries of physiology and pharmacology. Trends Pharmacol Sci 1999; 20: 370-5.

115 Lerner MR. Tools for investigating functional interactions between ligands and G-protein-coupled receptors. Trends Neurosci 1994; 17: 142-6.

116 Wise A, Jupe SC, Rees S. The identification of ligands at orphan G-protein coupled receptors. Annu Rev Pharmacol Toxicol 2004; 44: 43-66.

117 McLatchie LM, Fraser NJ, Main MJ, Wise A, Brown J, Thompson N, et al. RAMPs regulate the transport and ligand specificity of the calcitonin-receptor-like receptor. Nature 1998; 393: 333-9.

118 Hay DL, Poyner DR, Sexton PM. GPCR modulation by RAMPs. Pharmacol Ther 2006; 109: 173-97.

119 Galvez T, Duthey B, Kniazeff J, Blahos J, Rovelli G, Bettler B, et al. Allosteric interactions between GB1 and GB2 subunits are required for optimal $\mathrm{GABA}_{B}$ receptor function. EMBO J 2001; 20: 2152-9.

120 Jones KA, Borowsky B, Tamm JA, Craig DA, Durkin MM, Dai M, et al. $G A B A_{B}$ receptors function as a heteromeric assembly of the subunits $\mathrm{GABA}_{B} \mathrm{R} 1$ and $\mathrm{GABA}_{B} \mathrm{R} 2$. Nature 1998; 396: 674-9.

121 Robbins MJ, Calver AR, Filippov AK, Hirst WD, Russell RB, Wood MD, et al. $\mathrm{GABA}_{\mathrm{B} 2}$ is essential for g-protein coupling of the $\mathrm{GABA}_{B}$ receptor heterodimer. J Neurosci 2001; 21: 8043-52.

122 Lagerstrom MC, Schioth HB. Structural diversity of G protein-coupled receptors and significance for drug discovery. Nat Rev Drug Discov 2008; 7: 339-57. 